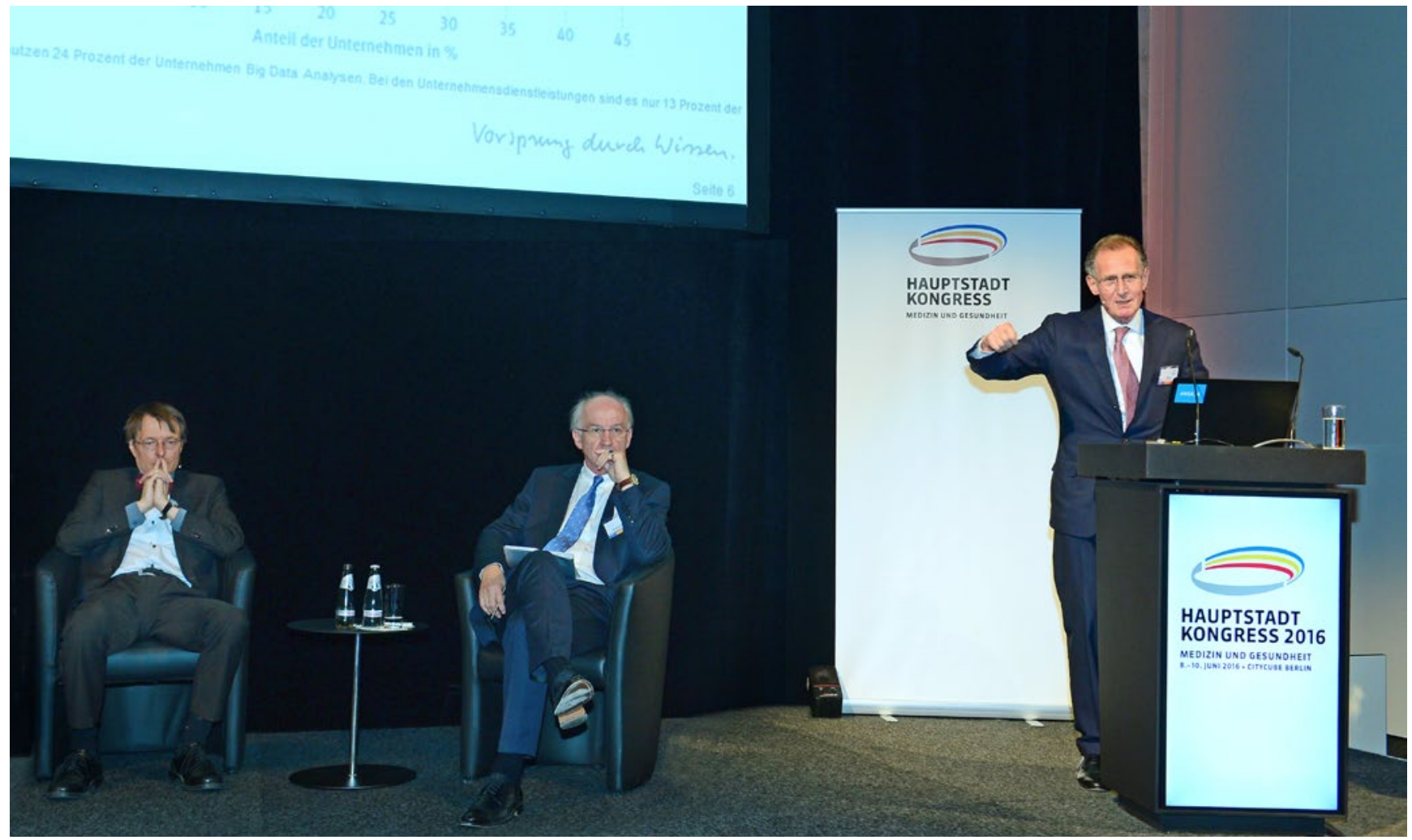

Digitale Revolution: Johann-Matthias Graf von der Schulenburg (mi.) leitet die Diskussion zwischen Bert Rürup (re.) und Karl Lauterbach.

\title{
Systemwechsel der Krankenversicherung durch Arbeit 4.0
}

Es ging um nichts Geringeres als die Zukunft des Gesundheitswesens angesichts der sich verändernden Arbeitswelt, als sich zwei Schwergewichte der Gesundheitspolitik auf dem Podium des Hauptstadtkongresses trafen: Prof. Dr. Dr. Karl Lauterbach (SPD), Mitglied des Bundestages, Direktor des Instituts für Gesundheitsökonomie der Universität zu Köln und Vordenker der Bürgerversicherung, sprach anderthalb Stunden lang mit Prof. Dr. Dr. h.c. Bert Rürup, Präsident des Handelsblatt Research Institutes Düsseldorf, ehemaliger Wirtschaftsweiser und Professor für Wirtschaftspolitik an der TU Darmstadt.

Über die Geschichte der industriellen Revolutionen sprangen die Referenten mitten hinein in die heutige, die digitale Revolution des Arbeitsmarktes, Arbeit 4.0 genannt, die möglicherweise erhebliche Auswirkungen auf die Beschäftigung und damit auch auf die Beiträge der Sozialversicherungspflichtigen zur Krankenversicherung haben wird. „Arbeit wird sich verändern“, sagte Rürup in seinem Eingangsstatement. „Wir werden mit der Fragmentierung, Polarisierung und Entbetrieblichung der Arbeit zu tun haben." In der Folge komme es dazu, dass es neue, hoch bezahlte Tätigkeiten geben werde, aber auch viele Routinearbeiten, die weiter entwertet würden.

Auch die Zahl der sogenannten Solo-Selbstständigen, die von ihrem Schreibtisch zu Hause arbeiten, wird Rürup zufolge rasant zunehmen. Durch die Digitalisierung würde Arbeit außerdem die lokale Bindung weiter verlieren. Besonders gut verdienen werden diese Solo-Selbstständigen, für die es bereits den klangvollen Namen der Gig-Economy gibt, nicht, machte der
Wirtschaftsexperte deutlich. Denn sie arbeiteten nach Auftragslage und Zuruf - mal mehr, mal weniger. „Damit wird es zu einer Erosion der Beitragsgrundlage für die Sozialversicherung kommen“, verdeutlichte Rürup. Denn Selbstständige seien nicht versicherungspflichtig. „Es besteht nur die Möglichkeit, die Anreize zu nehmen, sich selbstständig zu machen“, schlug Rürup als Lösungsansatz vor.

\section{„Duales System hat sich überlebt"}

SPD-Gesundheitspolitiker Lauterbach machte das Problem weniger an der Selbstständigkeit fest als am dualen System von gesetzlicher und privater Krankenversicherung (GKV und PKV). „Das Nebeneinander von GKV und PKV ist ein Systemproblem, das eine gute Lösung extrem erschwert“, sagte Lauterbach und läutete damit schon mal den Bundestagswahlkampf 2017 ein, in dem es dann auch wieder um die bereits vor drei Jahren propagierte Bürgerversicherung gehen wird. Die Zukunft der Krankenversicherung setze einen Systemwechsel voraus, ist Lauterbach überzeugt. Eine Zukunft für die PKV als Vollversicherung sieht er nicht. „Das duale System hat sich überlebt“, betonte er, und die PKV werde sich in nicht allzu ferner Zukunft „ganz von allein erledigen“: Junge Leute scheuten den Wechsel in die PKV, für die Älteren würden die Beiträge im Alter unbezahlbar und an den Finanzmärkten könne die PKV keine Einkünfte mehr erzielen. Die GKV hingegen sei gut durch die Finanzkrise gekommen, sei bei den Patienten akzeptiert und könne schnell auf Innovationen reagieren. 